\section{Brought down to Earth}

With its unique access

to Mir cosmonauts,

Moscow's Institute for

Biomedical Problems

was a world leader for

space biology. But now

it is working under

greatly diminished

circumstances, says

Quirin Schiermeier.

W hen the flaming remnants of the Mir space station plunged into the South Pacific on 23 March it marked not only the end of a successful mission, but of an era of human space flight. This expensive and risky pursuit, no longer the ambition of single nations, is now a global partnership.

For the next decade, human activities in space will be dominated by the International Space Station (ISS). And Anatoli Grigoriev, director of the Institute for Biomedical Problems (IBMP) in Moscow, has mixed feelings about this state of affairs. Without the ISS, his institute would have no future. Yet the IBMP's involvement in the project will be very different from the scientific autonomy it enjoyed on Mir. "We used to be hosts, but now we are only guests," Grigoriev laments.

Grigoriev's career has spanned the rise and fall of the Russian space programme. $\mathrm{He}$ joined the IBMP as a medical graduate in 1966, just five years after Yuri Gagarin's pioneering flight had electrified the nation. Working on the regulation of blood salt levels under microgravity, he rose through the ranks until he was appointed to his present position in 1988.

The IBMP, with a complement of some 4,000 scientists, engineers and technicians, was then at its zenith. Although the cracks were beginning to show, the Soviet Union was still a genuine superpower. The space programme, for which the IBMP provided full medical support, was the nation's pride and joy, and the first module of Mir had been launched just two years before. "That time was a unique and fulfilling experience," says Valeri Bogomolov, one of the institute's deputy directors.

Through experiments on animals sent

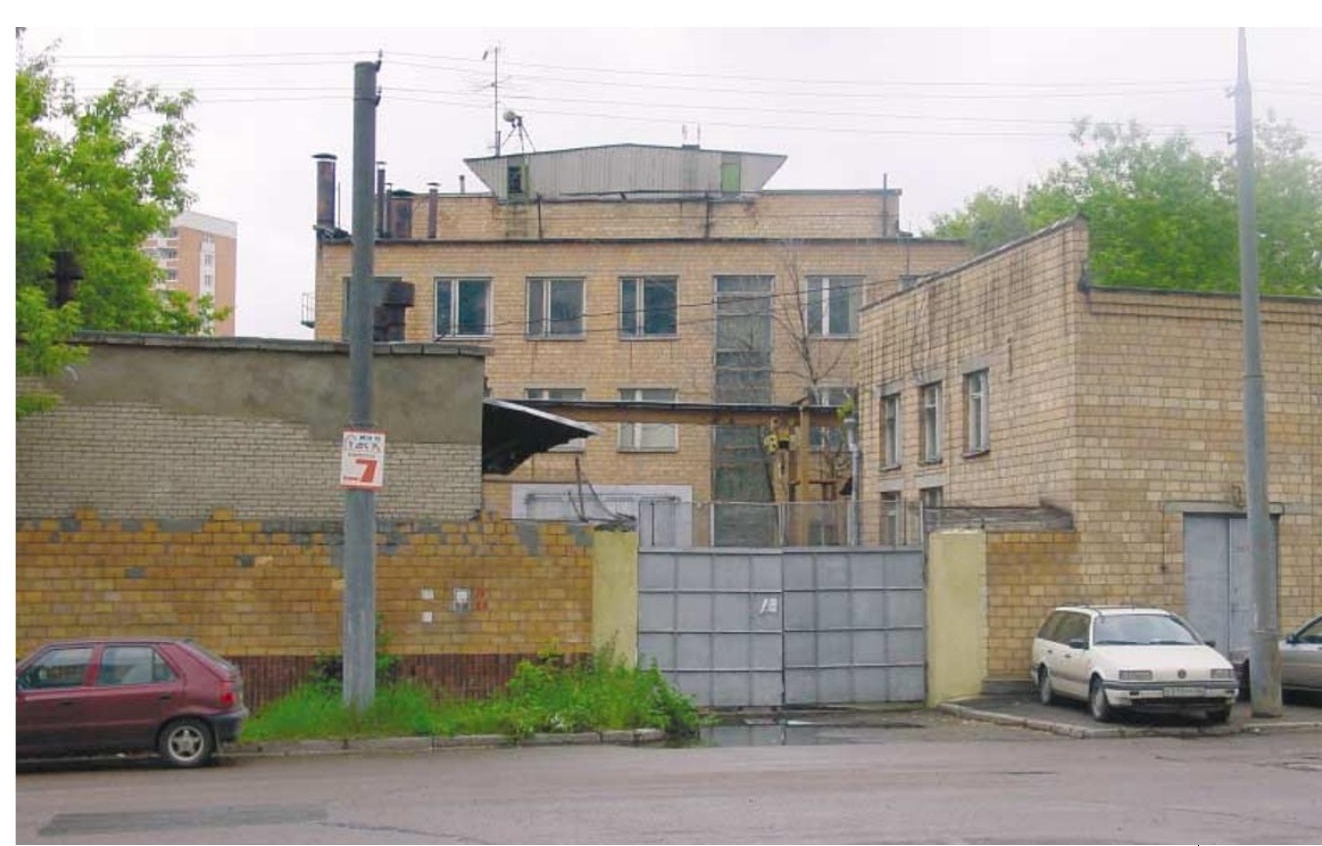

Run down: the Institute for Biomedical Problems in Moscow is a shadow of its former self. Run by Anatoli Grigoriev (below), it has housed well-known scientists, including Inesa Kozlovskaya (bottom).

into orbit, the IBMP had built up its expertise on the biological effects of space flight. But it was the institute's work on Mir cosmonauts, investigating the physiological effects of long-duration space flight, that dominated its agenda under Grigoriev's leadership. IBMP scientists studied how the body adapts to microgravity, and developed countermeasures, such as exercise regimes and gravity-simulation suits. Many other aspects of space research — including water conservation, microbiology and radiation biology — were also tackled.

\section{Decline and fall}

But this work was set against a background of steady decline. As research budgets dwindled after the break up of the Soviet Union, Grigoriev's institute had farther to fall than most. Today the IBMP, housed in a series of run-down brick buildings on the outskirts of Moscow, has lost $90 \%$ of the staff it had in 1988.

The IBMP's fortunes were mirrored, more publicly, by those of Mir. The station was originally intended to operate until 1991. But when it became clear that Russia could not afford to launch a successor, the space programme's efforts became focused on keeping Mir alive. More modules were added, the last in 1996. In the meantime, Mir cosmonauts set endurance records: Valeri Polyakov, now a deputy-director at the IBMP, stayed in orbit for an unmatched 437 days and 18 hours in 1994-95, conducting medical observations on fellow crew members.

But by 1997 the rot had set in. Mir suffered a fire, computer failures and a collision with a supply vehicle that depressurized one module. In the Western media, Mir was lampooned as an orbiting rust bucket. Its
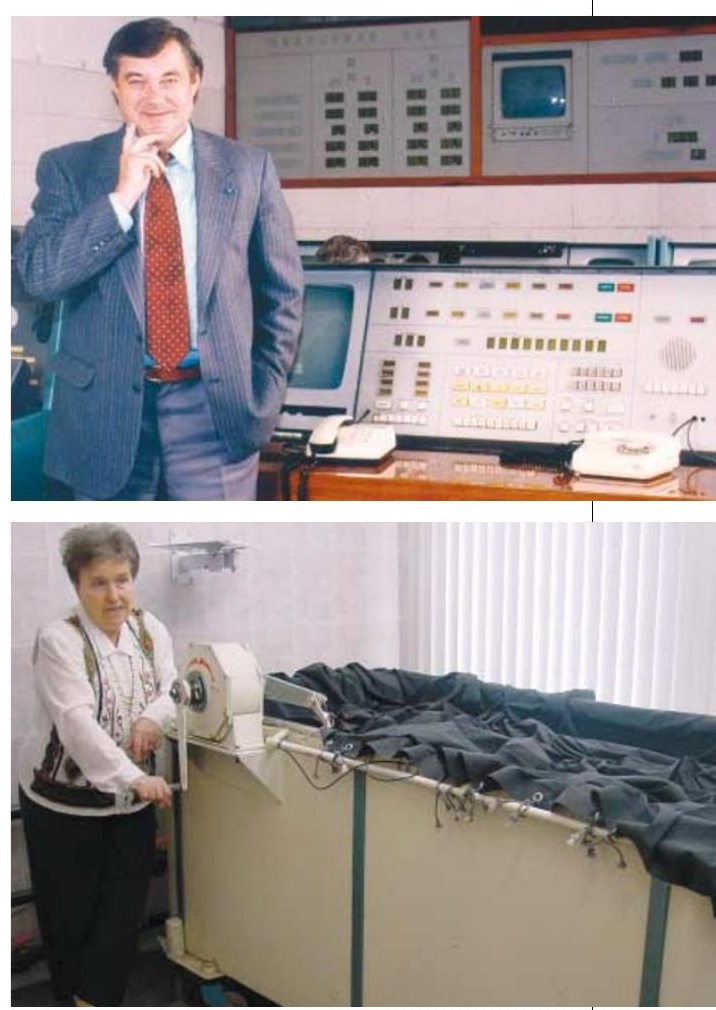

commander, Vasili Tsibliev, whose health declined as disaster followed disaster, was presented as a pathetic figure, in contrast to the heroic portrayal of the NASA astronaut Michael Foale, who was on Mir at the same time. For staff at the IBMP, it was a dispiriting experience. "It was a very difficult situation," says Bogomolov.

The station's demise has deepened the depression at the institute. The IBMP is now preparing for research on the ISS and, in principle, Russia is an equal partner. But in practice, financial constraints have made 
完
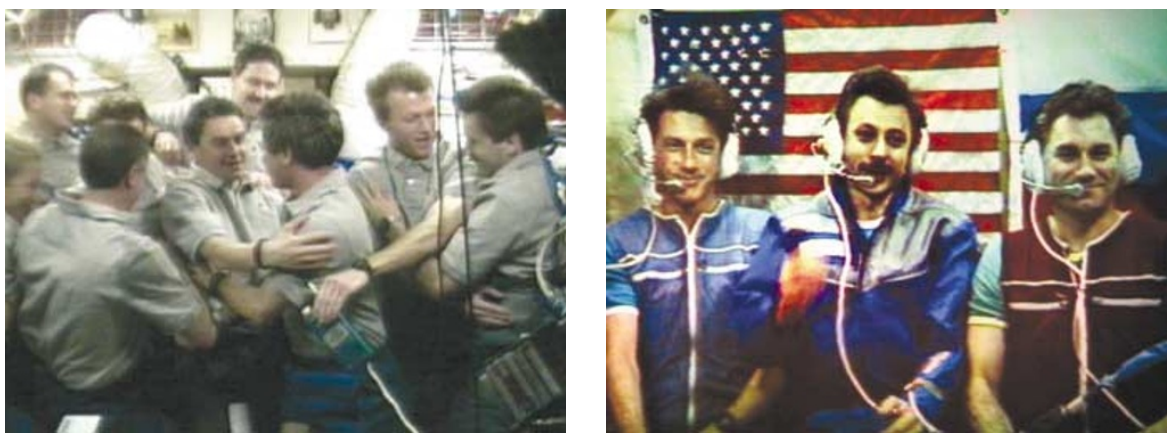

Former glories: Russian-American crews on board the Mir space station. On the right, commander Vasili Tsibliev (right) is shown with Alexander Lazutkin (centre) and American Michael Foale.

the former superpower a space wallflower.

Russia's Zvezda service module, docked onto the ISS in July 2000, could be financed only by selling 4,000 hours of Russia's total research time aboard the first phase of the ISS - more than half of its total allocation.

Many of the IBMP's staff fear that this deal, struck in 1998, will be the start of a larger sell-off. Russia, although invited, is not participating in the International Life Science Working Group that is managing the selection of biology and medical research proposals for the ISS. Russia says it cannot afford to join this club, whose members have pooled their experimentation time and facilities. Staying away gives Russia the option of selling more of its allocated research time. But it also means that Russia will be scientifically isolated on the ISS.

\section{Isolation station}

That is unfortunate, because the IBMP's separation from the international scientific community has been a long-standing problem. The institute does have some researchers who are recognized as world leaders in their fields - neurophysiologist Inesa Kozlovskaya, for example, has published more than 250 papers in Englishlanguage journals. But she is an exception. Founded as a military institute, much of the IBMP's research was published only in Russian, and often restricted to reports delivered to senior officials. Tellingly, when Nature handed Grigoriev the latest issue of the journal, it was the first copy he had ever opened.

Since the end of the Cold War, international collaborations have opened up. In 1991, NASA, the US National Space Biomedical Research Institute in Houston and the IBMP agreed to exchange physiological data. Many Western space agencies sent astronauts to Mir, and ground-based collaborations have also been established (see 'Cosmonauts behaving badly', right).

Most scientists who have collaborated with the IBMP are positive about the experience. But they warn that good personal contacts are needed to ensure that things run smoothly. "It is essential that the modes of operation of a joint project, its scientific goals, and the methods and statistical tools to be applied are defined in detail," says Rupert Gerzer, director of the Institute of Aerospace Medicine in Cologne, part of DLR, the German aerospace research agency. "Otherwise you can experience unpleasant surprises.”

Ary Goldberger of Harvard Medical School has carried out research on heartbeat dynamics using IBMP data. "The Russian data were invaluable," he says. "Immortalizing their unique data in an open archive should be a major priority." The Russian data are not always well collated, says Goldberger. But he adds that he has also experienced problems in obtaining data from NASA.

Grigoriev works hard to dispel reservations about working with the IBMP, and points to the institute's unique experi- ence in providing medical support for longduration space missions. "Much is hard for us to do these days," he says. "But without Mir there would be no ISS."

"Russia's long-term background in the area is very valuable," says Victor Schneider, of NASA's life-sciences division. "But the Russian programme, limited in scale, has only whetted our appetite."

Grigoriev agrees that additional research is necessary, in particular on bones, red blood cells, metabolism, and the cardiovascular and immune systems. How much of a contribution the IBMP's scientists make to this work may depend on the health of Russia's fragile economy. But Grigoriev believes that western scientists and space agencies have more to gain from working with the IBMP than just access to its data from Mir. "There are differences in scientific traditions, customs and ambitions," he says. "We have not yet learned the best from each other."

Until now, cultural differences in the approach to human space-flight have tended to cause tensions, with NASA's buttoneddown approach clashing with the Russian penchant for improvization. But as long as the IBMP remains part of the ISS, Russia's cosmonauts will have the chance to show that they still have something to contribute.

Quirin Schiermeier is Nature's German correspondent.

http://www.ibmp.rssi.ru/webpages/engl/welcom.html

\section{Cosmonauts behaving badly}

It is 2016. A highly trained multinational crew is midway through an eight-month flight to Mars. But tensions are rising. Russian and American crew members start yelling at each other, then a fight breaks out. Mission control is helpless.

Such scenarios cannot be ignored, suggests a space-flight simulation experiment carried out between June 1999 and April 2000. Three test groups spent prolonged periods in a mock-up of the Mir space station at the Institute for Biomedical Problems (IBMP). One group of four Russians was cooped up for 240 days; two other international groups joined them for 110 days each. The crew members' behaviour, health and interactions were recorded and analysed by teams of Russian, Canadian, German and Japanese psychologists.

Conflicts occurred between different crews and individual crew members. Tensions culminated at a New Year's party in the camera-free kitchen. After a fist fight between two members of the Russian crew, one of the combatants tried to embrace and kiss a female Canadian member from the other group — the only woman on board - against her will.

Following the incident, Russian mission control decided to close a hatch to separate the two groups, and a Japanese crew member quit the experiment. When the Canadian eventually emerged from the Mir mockup, she told the press that she had been sexually harassed, and is now suing the Canadian Space Agency, the IBMP and Vadim Gushin, the study's scientific coordinator.

The New Year incidents also generated distrust among the IBMP's collaborators. Gushin accepts that there were communication problems, but prefers to stress the lessons to be learned for the International Space Station. "Lack of confidence in the Russian mission control caused a constant feeling of psychological discomfort among non-Russian crew members," he says. Rather than the current practice, in which NASA and the Russian Space Agency operate separate mission-control teams, Gushin argues that the teams should be integrated to include representatives of all nationalities on board. 